\title{
The Giving Standard: Conditional Cooperation in the Case of Charitable Giving
}

Pamala Wiepking, VU University Amsterdam, the Netherlands (P.Wiepking@fsw.vu.nl)

Merijn Heijnen, Amsterdam City Counsel, the Netherlands (M.Heijnen@yahoo.com)

Paper prepared for resubmission to the International Journal of Nonprofit and Voluntary Sector Marketing

December 28, 2009

3,720 words

\begin{abstract}
(128 words)
In this study, we make a first attempt to investigate the mechanisms of conditional cooperation in giving outside experiments, using retrospective survey data on charitable giving (the Giving the Netherlands Panel Study 2005, N=1,474). Our results show that in the case of door-to-door donations, social information affects perceived social norms for giving and, through this perception, influences the level of actual donations. The effect of social information on actual door-to-door donations is fully mediated by perceived social norms for giving. Furthermore, we found empirical support for the giving standard hypothesis. People in different income categories donate roughly the same amounts in separate instances (they use the same social information), and as a result people in lower income households donate a higher percentage of their income to charitable organizations.
\end{abstract}




\section{The Giving Standard: Conditional Cooperation in the Case of Charitable Giving}

\section{Introduction}

In a relative sense, the poor are known to be more generous charitable donors than those who are financially better off. People with a lower income often donate a higher percentage of their income to charitable organizations than people with an average income (Hoge and Yang, 1994; Independent Sector, 2002; James III and Sharpe, 2007; Jencks, 1987; McClelland and Brooks, 2004; Schervish and Havens, 1995). But why is that the case? Literature suggest several explanations (e.g., Jencks, 1987; Schervish and Havens, 1995), but one shortfall in many studies on charitable giving that examine the relationship between income and giving is the lack of (empirically-tested) explanations for the proportional higher donations of the poor. However, there are some ad hoc explanations. Jencks (1987) and Schervish \& Havens (1995) for example suggest that theoretically, the high proportional donations of those with a lower income can be explained by the religious poor, who donate disproportional amounts to their church. This is labeled the 'sect' effect. Iannaconne (1988) does show that in the U.S. lower income households belong disproportional to sect and sect-like religious denominations, and members of these sects donate the highest proportion of income to religious organizations. In a direct test of the 'sect' effect of giving in the Netherlands, Wiepking $(2007$; 2008) finds a stronger negative effect of income on proportion of income donated to religious organizations compared to all organizations. However, this stronger negative effect cannot be explained with higher religious participation of lower income groups.

Another explanation for the higher proportional donations of lower income households is given by James \& Sharpe (2007). They argue that a 'low income, high asset' effect can account for the higher proportional donations of lower income households. James and Sharpe find that, in the United States, high committed donors (households that donate over $10 \%$ of their after-tax income) with a lower income actually have higher levels of wealth than noncommitted lower income households. These higher levels of wealth could explain the higher proportional donations of lower income households. Wiepking (2007) showed that the 'low income, high asset' explanation could not explain the higher proportional donations of lower income households in the Netherlands.

Finally, Wiepking (2007) suggests that the higher proportional donations of the poor can be explained by the giving standard hypothesis. This giving standard refers to norms concerning the level of donations in specific situations that people in different income groups share. Many people donate the same amounts when -for example- making donations in a door-to- 
door collection or in response to a direct mail letter. This implies that many people in middle and higher income groups donate only slightly higher absolute amounts than people in lower income groups, when considering separate incidences of giving. Consequently, the total donations of people with a lower income consist of a larger proportion of their income than the total donations of people with a higher income. Again, this explanation was not empirically tested.

Experiments conducted by social psychological and economists show that many people are 'conditionally cooperative' when it comes to making public good contributions (Fischbacher, Gachter, and Fehr, 2001; Frey and Meier, 2004; Keser and Winden, 2000). People who are conditional cooperators are willing to contribute more to a public good the more others contribute. Could conditional cooperation lead to a giving standard and explain the negative relation between income and proportional donations? In this study, we will use the Giving in the Netherlands Panel Study 2005 (GINPS05; N=1,474) in order to answer this question.

\section{Conditional cooperation in the case of charitable giving}

Experimental results show that the charitable behavior of others does indeed influence ones own giving behavior, as expected from conditional cooperation. In a natural field experiment, Heldt (2005) studies conditional cooperation in the case of donations for the preparation of ski tracks in Sweden among cross country skiers. He finds evidence in support of the conditional cooperation hypothesis, as the probability that Swedish cross country skiers donate is higher when their belief of others' contribution is increasing.

Not only does conditional cooperation increase the contribution rate, it also affects the level of donations. People donate more money when they have information that other people also donate more. In a public goods experiment conducted by Fischbacher et al. (2001) 50\% of the respondents show conditional behavior that affected their level of contributions. When these conditional cooperators received information about an increase in the average contribution of other participants, they increased their own contribution with nearly the same amount. In a natural field experiment, Alpizar, Carlsson, \& Johansson-Stenman (2007) provided visitors to a National park in Costa Rica with reference information on the donations of others. They found that providing a smaller reference amount decreases the size of the contribution, just as providing a larger reference amount increases it. In another field experiment, Shang (2008) used a fundraising campaign by a public radio station to show how social information can influence individual donations. Listeners who called the radio station to make a pledge were 
informed about a (fictional) donation, made by a previous caller. Providing manipulated information about relatively high donations of others significantly increased the contributions. In addition Shang finds that the information about other people's donations affects the donor's belief of what others are contributing, thus directly influencing the donor's perceived norms on charitable giving: those who believe others give more contribute more themselves. Using an experimental study Shang demonstrates that these perceived norms actually fully mediate the effect of information about other donations on the giving levels of individuals. In other words, the given social information affects the perceived social norms and, through this perception, influences the level of donations.

$<<$ Insert figure 1 about here $>>$

Figure 1 displays the conceptual model of conditional cooperation in the case of charitable giving as suggested by Shang (2008). Social information on giving by other donors determines peoples' perceived social norms for giving, which in turn determine people's actual donating behavior.

In experiments, participants are provided with social information by experiment leaders. However, in real life, when deciding on the level of charitable giving, it is less clear how people find and evaluate social information. Cialdini \& Goldstein (2004) argue that norms about appropriate contributions are often deduced from the behavior of others. We assume that people evaluate the charitable behavior of others in their social network, and use this as social information on giving. We thus argue that when people display conditional cooperative behavior in the case of charitable donations, they will use social information based on giving behavior present in their social networks to formulate perceived social norms for giving, which in turn affects their level of giving.

In this study, we will make a first attempt to investigate the mechanisms of conditional cooperation in giving outside experiments, using retrospective survey data on charitable giving. We will start by investigating how social information on giving relates to people's perceived social norms for giving. Secondly, we will show whether the relationship between social information and giving is mediated by the relationship between social norms and giving. We will conclude with showing the consequences of conditional cooperation in giving behavior for the giving standard hypothesis. 


\section{Data and measurements}

In this study, we make a first attempt to investigate the mechanisms of conditional cooperation in giving outside experiments, using retrospective survey data on charitable giving. We use the third wave of the Giving in the Netherlands Panel Study 2005 (GINPS05, 2005). The GINPS is a bi-annual longitudinal survey study on charitable giving and volunteering in the Netherlands, which started in 2001. In May 2006, 1,868 persons were questioned about their donating behavior in 2005. In total, 1,474 respondents (79\%) completed the questionnaire, using Computer Assisted Self-Administered Interview procedures (CASI). After using a weight factor based on age, sex and urbanization, the data are representative of the Dutch population. GINPS05 includes behavioral information on amounts donated in specific incidences of giving, demographic characteristics, as well as attitudinal information on amounts that are considered appropriate to give in specific instances of giving both for others (social information) and for oneself (perceived social norms).

We measured social information on giving by asking respondents what amount they believe that others give each time they donate with one of three different methods: in response to a door-to-door collection, in response to a direct mail letter, and by means of regularly scheduled payments (the latter not specifically following a request). These three methods of giving are omnipresent in the Netherlands, as well as in other Western countries (ACOSS, 2005; CAF, 2006; Imagine Canada, 2006; Jackson and Latané, 1981; Sargeant and Hudson, 2008; Weyant, 1996). In 2005, 91\% of the Dutch households donated by means of a door-todoor collection, $30 \%$ donated by means of a direct mail letter, and $49 \%$ donated by means of a (regularly) scheduled payment. By selecting these three methods of giving, we hope to capture the effects of social information about different types of donations.

The question on social information was phrased in a way that respondents would name the actual amount they believed others would donate with the three methods of giving. It specifically did not mention the option of an expected donation of zero euro. However, some respondents expected others to not donate at all and answered that they believed others would give zero euro.

We measured perceived norms on giving by asking respondents what amount they find appropriate to give when they donate money themselves in response to a door-to-door collection, in response to a direct mail letter, and by means of a regularly scheduled payment. Finally, we measured actual giving behaviour by selecting people who had been solicited to make a donation in a door-to-door collection and had received a direct mail letter in the two 
weeks prior to the survey, and ask them whether and how much they had given in response to these requests. Note that social information on giving and perceived norms on giving were subsequent questions, asked in the beginning of the questionnaire. The question on actual amount donated in a response to a door-to-door and direct mail solicitation was asked separately halfway through the questionnaire. Actual amount donated was part of a larger item that asks people whether or not they were asked to donate to charitable organizations in the two weeks prior to the questionnaire, for a number of methods. People who indicated having received a request to make a donation in a door-to-door (42\%) or direct mail solicitation $(16 \%)$ over the past two weeks were asked how much they donated in these instances. When people donated nothing in response to these requests, they were given value 0 .

Annual after-tax household income was measured by asking respondents about their own and (if applicable) their partner's monthly after-tax income from eight different sources (paid work, welfare payments, social security benefits-unemployment, disability, and 'other'-, pension, student benefits, and alimony). Respondents choosing not to state their exact income were offered indicative categories, which were recoded to the mean value, resulting in no missing values on the income variables. Total monthly after-tax income was calculated by adding all sources of income, multiplying by twelve to create an annual estimate and combining respondent and partner income (where applicable) to create a total for each household. Median annual after-tax household income is $€ 24,000$, highest income is $€ 370,000$. Comparison with annual after-tax household income of the Dutch population indicates that the respondents in GINPS05 are representative for lower to middle-high income households (Statistics Netherlands, 2008). We use both income in ten categories and the natural log of annual after-tax household income in the analyses. Table 1 gives an overview of the variables used in the analyses.

$$
<<\text { Insert table } 1 \text { about here }>>
$$

\section{Results}

From experiments on the role of social information in giving, Shang (2008) derived the conclusion that social information on giving by other donors determines peoples' perceived social norms for giving, which in turn determine people's actual donating behavior. How does the social information on giving for respondents in the GINPS05 survey relate to their perceived social norms for giving? 
$<<$ Insert figure 2 about here $>>$

Figure 2 shows the mean amount of donations respondents believe others to give (social information on giving) and the mean amount of donations they themselves find appropriate to give (perceived social norms for giving). For all types of giving the social information is on average slightly higher than the perceived social norms. It is interesting that people believe others should give more than they should give themselves. Paired samples tests show that the social information and perceived social norms for direct mail giving ( $\mathrm{t}$-value $=-2.28 ; p \leq .05$ ) and regularly scheduled payments ( $\mathrm{t}-\mathrm{value}=-2.32 ; p \leq .05)$ do differentiate significantly. There is no significant difference between social information and perceived social norms for doorto-door donations.

\section{Social information, perceived norms and giving}

In figure 1 we showed the conceptual model for mediation of the relationship between social information and actual giving by perceived social norms, based on the experimental results from Shang (2008). We now investigate whether the relationship between social information and actual giving is mediated by perceived social norms in the case of reported door-to-door and direct mail donations. Figure 3 a shows the standardized coefficients for relationships between social information, perceived norms, and actual giving in door-to-door giving.

$$
<<\text { Insert figure } 3 \text { a about here }>>
$$

The results of a Sobel's test for mediation show that the effect of social information on actual amount donated in door-to-door giving is fully mediated by perceived social norms (Sobel zvalue $=6.38, p \leq .001)$.

Figure $3 \mathrm{~b}$ shows the beta coefficients for relationships between social information, perceived norms, and actual giving for direct mail donations. The results of a Sobel's test for mediation show that the effect of social information on actual amount donated in direct mail giving is not mediated by perceived social norms (Sobel z-value=n.s.).

$<<$ Insert figure $3 \mathrm{~b}$ about here $>>$

Further analyses show that when we exclude the nondonors (respondents that were asked to make a donation with a direct mail letter two weeks prior to responding to the questionnaire, 
but did not comply; $\mathrm{N}=161,11 \%$ of respondents requested) from the analyses, we find complete mediation of the social information effect on direct mail donations by perceived social norms. ${ }^{1}$

\section{Results of conditional cooperation for the giving standard}

Figure 4 shows the relationship between different income categories and both perceived social norms and actual donation in door-to-door and direct mail giving. Figure 4 shows that there is no clear relationship between income categories and both perceived social norms and actual donation in the case of door-to-door giving. This is confirmed by both insignificant results in an ANOVA test of differences between income categories for perceived social norms and actual donation, and by the insignificant correlation between the natural log of income and both perceived norms and actual donation in door-to-door giving.

\section{$<<$ Insert figure 4 about here $>>$}

The relationship depicted in figure 4 between perceived social norms and actual donation in the case of direct mail giving is less clear. There is a slight resemblance to a U-shaped relation between mean perceived social norm and income categories. The results of an ANOVA test show that there are no significant differences between the income groups in perceived social norms for direct mail giving. There is also an insignificant (negative) relationship between income and perceived social norms for direct mail giving (Peason's r=-.042; n.s.). We thus find no significant differences between the actual donation in direct mail giving and both income in categories and the natural log of income.

We can conclude that people in different income categories share approximately the same perceived norms for giving, affecting the level of their actual donation in the case of door-todoor donations and direct mail donations. This is empirical support for the giving standard, as suggested by Wiepking (2007). Many people in middle and higher income groups donate approximately the same absolute amounts than people in lower income groups, when considering separate incidences of giving. Consequently, the total donations of people with a lower income consist of a larger proportion of their income than the total donations of people with a higher income. We find that the perceived social norms as discussed in the theory of

\footnotetext{
${ }^{1}$ Results available from the author. In the case of door-to-door donations, the effect of social information on donations is fully mediated by perceived social norms, both when the nondonors are included and when they are excluded from the analyses.
} 
conditional cooperation are approximately similar for different income groups, indicating an absolute giving standard, which can explain the negative relationship between income and proportional donations.

\section{Conclusion and discussion}

In this study, we investigated the mechanism of conditional cooperation in charitable giving, using retrospective survey data. Our results show support for the theory of conditional cooperation in the case of door-to-door donations (Fischbacher, Gachter, and Fehr, 2001; Frey and Meier, 2004; Shang, 2008). Social information on giving affects perceived social norms on giving and, through this perception, influences the level of donations. The effect of social information on actual door-to-door donations is fully mediated by perceived social norms for giving.

In the case of direct mail donations, we find that the effect of social information on giving is fully mediated by perceived social norms for giving when only donors are considered, but not when both donors and nondonors are considered. One post hoc explanation for this result is that there is a selection effect: Only people willing to make donations in direct mail campaigns in the first place are susceptible to social information on donations. The fact that we do not find the same selection effect in the case of door-to-door donations could be because of the differences in percentage of people making donations with these methods over the course of a year: $91 \%$ makes a donation in a door-to-door campaign and $30 \%$ in a direct mail campaign. With $91 \%$ of the people making donations in a door-to-door campaign, there can hardly be a selection effect.

Another explanation for the different results for door-to-door donations and direct mail donations relates to the different mechanisms that determine giving with these methods. Bekkers and Wiepking (2007) identified eight theoretical mechanisms that promote charitable giving. ${ }^{2}$ The clearest mechanism at work in the case of both door-to-door and direct mail donations is the solicitation mechanism. People are requested to make a donation. However, the two solicitations differ strongly on another mechanism: reputation. The door-to-door donation is directly observable by the person soliciting for the charitable organization. ${ }^{3}$ Not giving will negatively affect someone's social reputation. Experimental studies show that the

\footnotetext{
${ }^{2}$ The eight mechanisms Bekkers and Wiepking identified are (1) awareness of need; (2) solicitation; (3) costs and benefits; (4) altruism; (5) reputation; (6) psychological benefits; (7) values; (8) efficacy.

${ }^{3}$ In the Netherlands, people conduct door-to-door solicitations for charitable organizations in their own neighbourhood. Often people know the person soliciting for a gift.
} 
more visible requests for gifts, the higher the comply rates (Hoffman, McCabe, and Smith, 1996).

Donations in direct mail campaigns on the other hand are mostly not observable by others: There are no social consequences of not giving. The mechanism at work in the case of direct mail donations is the psychological benefits mechanism. When giving entails positive psychological benefits, people are said to have positive personal norms (Schwartz, 1970). Personal norms strengthen the effect of social norms. When the social norm is to give, those who feel bad about themselves for violating the norm are more likely to give. Not giving would entail feelings of guilt, shame, or dissonance with one's self-image.

Thus people who have positive personal norms are more likely to reinforce these norms by making donations in direct mail campaigns. It is likely that specifically these people are susceptible to social information on giving. This would explain the limited support for the social information hypothesis in the case of direct mail giving.

Other studies have shown that social information on giving can be manipulated (e.g., Fischbacher, Gachter, and Fehr, 2001; e.g., Shang, 2008). Charitable organizations should provide potential donors with various financial resources with more tailored social information on donations. This could for example increase the likelihood of receiving higher donations from those with more financial capabilities. Furthermore, based on the results of this study, fundraisers should provide potential donors with social information (for example a specific amount other people donated in similar circumstances) on donations specifically when soliciting with methods that have high compliance rates, such as door-to-door or street campaigns, or when approaching people they believe are willing to make a donation. This will affect the perceived norms for giving (the amount the potential donor think he or she should give) and consequently the amount actually donated.

This is a first empirical test of the giving standard hypothesis. Wiepking (2007) argued that a giving standard could explain the negative relationship between income and proportional donations. Because people in different income categories donate approximately the same amounts in separate instances, lower income households donate a higher percentage of their income to charitable organizations.

Despite the clear merits of this paper, there are some methodological issues. First of all, our conclusions are based on Dutch data. It is difficult to assess whether we would have drawn similar conclusions when studying data relating to a different (cultural) context. The charitable sector in the Netherlands has a long history and the Dutch are known to be generous donors (Van Leeuwen, 1994; Salamon, Sokolowski, and List, 2003; Wiepking, 
2009; Wiepking and Bekkers, 2008). The Dutch might be more aware of the level of donations made by others than people in other countries, and it is hard to say how this might have affected our results. We do draw conclusions similar to Shang (2008), in her experimental studies on the effects of social information on giving in the United States. At least in the Netherlands and the United States, the effect of social information on donations is comparable. Secondly, our conclusions can only be generalized for donation instances in which people use door-to-door and direct mail giving, and to a lesser extent regularly scheduled payments. We expect that, for example, there might be differences in social information between people belonging to different religious denominations when other types of donations would be considered. Religiously affiliated people often make donations in church. Maybe people with different religious affiliations would differ significantly in their social information for giving in church. The limitation to only three types of donations is a clear disadvantage of our study. On the other hand, most experiments on conditional cooperation examine only one method of giving, and how it can be used to increase donor support. Future research would be welcome to better understand the importance of social information for charitable giving in other countries and cultural contexts. Furthermore, it would be very interesting to examine how the social information effect can be implemented by fundraising professionals to increase donor support. 


\section{References}

ACOSS. 2005. Summary of Findings. Giving Australia: Research on Philanthropy in Australia. Department of Family and Community Services: Canberra, Australia.

Alpizar F, Carlsson F, and Johansson-Stenman O. 2007. Anonymity, Reciprocity, and Conformity: Evidence from Voluntary Contributions to a National Park in Costa Rica. in Working Papers in Economics no. 245. Göteborg, Sweden: Department of Economics, Göteborg University.

Bekkers R and Wiepking P. 2007. Generosity and Philanthropy: A Literature Review. University of Notre Dame, Notre Dame, IN.

CAF. 2006. UK Giving 2005/06. Results of the 2005/06 Survey of Individual Charitable Giving in the UK. CAF, London, United Kingdom.

Cialdini RB and Goldstein NJ. 2004. Social Influence: Compliance and Conformity. Annual Review of Psychology 55: 591-621.

Fischbacher U, Gachter S, and Fehr E. 2001. Are People Conditionally Cooperative? Evidence from a Public Goods Experiment. Economics Letters 71: 397-404.

Frey BS and Meier S. 2004. Social Comparisons and Pro-social Behavior: Testing 'Conditional Cooperation' in a Field Experiment. American Economic Review 94: 1717-1722.

GINPS05. 2005. Giving in the Netherlands Panel Study 2005. VU University Amsterdam: [computer file]. Amsterdam, the Netherlands.

Heldt T. 2005. Conditional Cooperation in the Field: Cross-Country Skiers'Behavior in Sweden. Department of Economics and Society, Dalarna University, Sweden.

Hoffman E, McCabe K, and Smith VL. 1996. Social Distance and Other-Regarding Behavior in Dictator Games. American Economic Review 86: 653-660.

Hoge DR and Yang F. 1994. Determinants of Religious Giving in American Denominations: Data from Two Nationwide Surveys. Review of Religious Research 36: 123-148.

Iannaccone LR. 1988. A Formal Model of Church and Sect. American Journal of Sociology 94: S241-S268.

Imagine Canada. 2006. Canada Survey of Giving, Volunteering and Participating. Statistics Canada: Ottowa, Canada.

Independent Sector. 2002. Giving and Volunteering in the United States, 2001 survey. Independent Sector: Washington, DC.

Jackson JM and Latané B. 1981. Strength and Number of Solicitors and the Urge Toward Altruism. Personality and Social Psychology Bulletin 7: 415-422.

James III RN and Sharpe DL. 2007. The Nature and Causes of the U-Shaped Charitable Giving Profile. Nonprofit and Voluntary Sector Quarterly 36: 218-238.

Jencks C. 1987. Who Gives to What? In The Non-Profit Sector. A Research Handbook, Powell WW (eds.). Yale University Press: London; 321-339.

Keser C and Winden Fv. 2000. Conditional Cooperation and Voluntary Contributions to Public Goods. Scandinavian Journal of Economics 102: 23-39.

Van Leeuwen MHD. 1994. Logic of Charity: Poor Relief in Preindustrial Europe. Journal of Interdisciplinary History XXIV: 589-613.

McClelland R and Brooks AC. 2004. What is the Real Relationship between Income and Charitable Giving? Public Finance Review 32: 483-497.

Salamon LM, Sokolowski SW, and List R. 2003. Global Civil Society: An Overview. The Johns Hopkins Comparative Nonprofit Sector Project, Baltimore, MD.

Sargeant A and Hudson J. 2008. Donor Retention: An Exploratory Study of Door-to-door Recruits. International Journal of Nonprofit and Voluntary Sector Marketing 13: 89101. 
Schervish PG and Havens JJ. 1995. Do the Poor Pay More: Is the U-shaped Curve Correct? Nonprofit and Voluntary Sector Quarterly 24: 79-90.

Schwartz SH. 1970. Normative Explanations of Helping Behavior: A Critique, Proposal, and Empirical Test, Edited by Macaulay JB, L. Academic Press: New York.

Shang Y. 2008. The Effects of Social Information, Social Norms, and Social Identity on Giving. Department of Philanthropic Studies, Indiana University, Indiana, IN.

Statistics Netherlands. 2008. Household Income in Deciles in 2005. http://statline.cbs.nl/StatWeb/?LA=en [Accessed: October 13, 2008].

Weyant JM. 1996. Application of Compliance Techniques to Direct-Mail Requests for Charitable Donations. Psychology \& Marketing 13: 157-170.

Wiepking P. 2007. The Philanthropic Poor: In Search of Explanations for the Relative Generosity of Lower Income Households. Voluntas 18: 339-358.

- 2008. For the Love of Mankind. A Sociological Study on Charitable Giving. Department of Philanthropic Studies, VU Amsterdam, Amsterdam.

-. 2009. The State of Giving Research in Europe. Household Donations to Charitable Organizations in Twelve European Countries. Amsterdam: Pallas (Amsterdam University Press).

Wiepking P and Bekkers R. 2008. Differences in Charitable Giving in Europe. Presented at the DANS Conference "The Netherlands in Comparative Perspective". Den Haag, the Netherlands, November 13, 2008. 
Table 1 Description of the variables used in the study (GINPS05, 2005)

\begin{tabular}{|c|c|c|c|c|c|c|}
\hline & $N$ & Min. & Max. & Mean & Median & S.E. \\
\hline Social information door-to-door donation & 1223 & 0 & 250 & 3.23 & 2.00 & 10.36 \\
\hline Social information direct mail donation & 1160 & 0 & 500 & 8.66 & 5.00 & 20.53 \\
\hline Social information bank transfer & 1194 & 0 & 250 & 9.70 & 5.00 & 17.19 \\
\hline Yearly after-tax household income (ln) & 1474 & 0 & 12.82 & 9.89 & 10.09 & 1.25 \\
\hline Perceived social norms for door-to-door donation & 1332 & 0 & 200 & 2.98 & 2.00 & 7.90 \\
\hline Perceived social norms for direct mail donation & 1223 & 0 & 500 & 8.11 & 5.00 & 20.55 \\
\hline Perceived social norms for bank transfer & 1266 & 0 & 250 & 9.19 & 5.00 & 15.06 \\
\hline Actual amount donated in door-to-door collection & 614 & 0 & 107 & 3.14 & 2.00 & 8.68 \\
\hline Actual amount donated in direct mail campaign & 229 & 0 & 125 & 6.55 & 0.00 & 17.06 \\
\hline
\end{tabular}


Figure 1 Conceptual model for conditional cooperation 


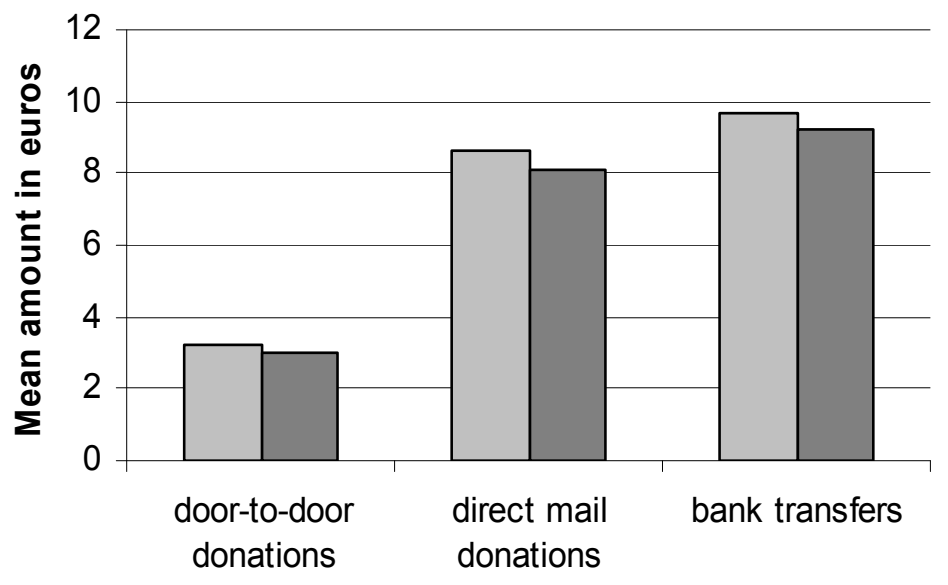

$\square$ social information $\square$ perceived social norms

Figure 2 Social information and perceived social norms for giving (GINPS05; weighted results) 
Figure 3a Beta (standardized) coefficients for relationships between social information, perceived norms, and actual giving in door-to-door giving $(\mathrm{N}=614$; beta coefficients in parentheses report the beta weights computed after the mediating relationship has been taken into account) 
Figure $3 \mathrm{~b}$ Beta (standardized) coefficients for relationships between social information, perceived norms, and actual giving in direct mail giving $(\mathrm{N}=229$; beta coefficients in parentheses report the beta weights computed after the mediating relationship has been taken into account) 

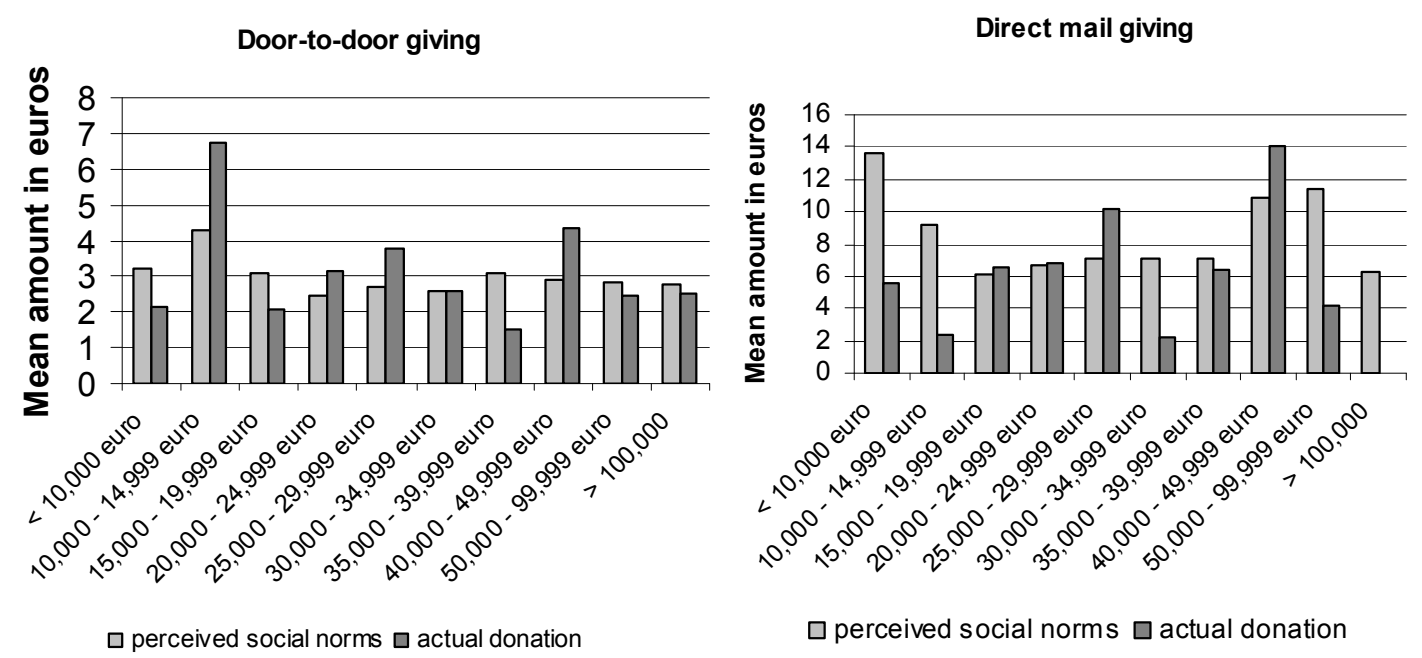

Figure 4 Perceived norms for giving and actual donation in door-to-door donations and direct mail donations by income category (GINPS05; weighted results) 